\title{
El dinamismo de las imágenes sagradas: análisis de las figuras de Marte, Término, Juventas y Júpiter en Antiquitates Rerum Divinarum 40-41, de Varrón
}

The Dynamism of Sacred Images: An Analysis of the Figures of Mars, Terminus, Juventas and Jupiter in Varro, Antiquitates rerum divinarum 40-41

\section{Guillermina Bogdan}

\section{OpenEdition}

Journals

Edición electrónica

URL: https://journals.openedition.org/mythos/3630

DOI: $10.4000 /$ mythos.3630

ISSN: 2037-7746

Editor

Salvatore Sciascia Editore

\section{Referencia electrónica}

Guillermina Bogdan, «El dinamismo de las imágenes sagradas: análisis de las figuras de Marte,

Término, Juventas y Júpiter en Antiquitates Rerum Divinarum 40-41, de Varrón », Mythos [En ligne], 15 | 2021, mis en ligne le 15 décembre 2021, consulté le 15 décembre 2021. URL : http://

journals.openedition.org/mythos/3630; DOI : https://doi.org/10.4000/mythos.3630

Este documento fue generado automáticamente el 15 diciembre 2021.

Mythos 


\section{El dinamismo de las imágenes sagradas: análisis de las figuras de Marte, Término, Juventas y Júpiter en Antiquitates Rerum Divinarum 40-41, de Varrón}

The Dynamism of Sacred Images: An Analysis of the Figures of Mars, Terminus, Juventas and Jupiter in Varro, Antiquitates rerum divinarum 40-41

\section{Guillermina Bogdan}

"Varro (...), tui libri quasi domum reduxerunt"

Cic. Ac. 1.9

1 En su estudio Rome's Holy Mountain. The Capitoline Hill in Late Antiquity, Moralee ${ }^{1}$ describe el espacio:

The Capitoline Hill has two summits: The southern one, facing the Forum Romanum and the Tiber River, was generally called the Capitolium in antiquity (or Capitolia or Mons Capitolinus); the northern one, facing the imperial forums and the Quirinal Hill, was called the Arx and The Tarpeian Rock. The hollow between these summits, the present location of the Piazza del Campidoglio, was called the inter duos lucos (place between the groves) and the Asylum. Crammed onto these three locations were dozens of holy places. The most important of them was the Temple of Jupiter Optimus Maximus, which stood on the Capitolium, the southern summit of the hill. The temple was originally dedicated in $509 \mathrm{BC}$ and reconstructed three times thereafter, the last time following its construction in $80 \mathrm{CE}$. (...). The shrines and altars standing on the hill included those for Terminus, Iuventas, Mars, the gens Iulia, Faustas Felicitas, Genius Publicus, Venus Vitrix, Fortuna Primigenia, Bellona, Jupiter Soter and Jupiter Depulsor. There were also places to venerate foreign cult such as Isis, Serapis, Anubis, Harpokrates, Jupiter Africus, Dea Caelestis, and Mithras. There were military memorials, treasuries, archives, a library and even a pool $^{2}$. 
2 Dicha descripción engloba y enlaza un conjunto de espacios considerados sagrados desde la antigüedad sin determinar con exactitud fechas, algunas de ellas imposibles de señalar. El recorrido al que el autor nos invita tiene como fuente una imagen en un momento determinado, pero, asimismo, supone una construcción que se hace no solamente con recursos arqueológicos sino también con fuentes históricas y míticoliterarias. Éstas últimas bien pueden no certificar una historicidad de la región, sí claramente cooperan en la construcción de la memoria cuyo diseño conforma la identidad del espacio.

3 Cancik $^{3}$ en 1985 define el concepto de "sacred landscape" como un sistema de signos y afirma:

Sacred landscape is a constellation of natural phenomena constituted as a meaningful system by means of artificial and religious signs, by telling names or etiological stories fixed to certain places, and by rituals which actualize the space. These "rules of combination" produce a text, which might be called "sacred landscape". The inventory of signs, the rules of combination, and the references to the ancient authors, which furnish materials (signs), grammar and interpretation (self-reference), build up a system, that experts in semiotics or aesthetics could mould into a coherent theory.

Por su parte, en la introducción a su trabajo, Edwards ${ }^{4}$ quien retoma a Cancik para profundizar en el estudio de la construcción de ciertos espacios, particularmente de la imagen de Roma, afirma que los textos romanos hacen eco de las asociaciones literarias e históricas sobre su ciudad tanto como de su aspecto material. De esta forma, siguiendo el concepto de ambos críticos, la imagen descripta por Moralee dialoga con los textos antiguos como dichos textos responden a lo que los propios autores romanos destacaron de la ciudad: las respuestas de éstos se volvieron parte de Roma influenciando a las visiones y a los escritos posteriores. Edwards ${ }^{5}$ destaca, entonces, cómo ciertos textos - agregamos - como el expuesto, dialogan tanto con la imagen material de un presente como con el pasado construido no sólo a partir de los monumentos que describen sino también a partir de las simbologías que los textos antiguos le transfirieron a esos restos materiales y funcionaron como estímulo a la memoria de eventos particulares.

5 Asimismo, teniendo en cuenta otros estudios sobre la espacialidad, Fitzgerald y Spentzou ${ }^{6}$ afirman que el espacio es un producto de un complejo intercambio: existe un lugar construido pero existe también un espacio producido culturalmente. Ese producto cultural depende de la lectura de códigos (significado de monumentos) pero también de interpretaciones que pueden incluir asociaciones históricas y míticas. Por su parte, Bendlin ${ }^{7}$, tomando el concepto de Pierre Nora (2008) lieux de mémoire, plantea que si bien existen estos eventos y acciones de importancia histórica que configuraron la identidad social y religiosa de la población de Roma, no hay una relación inequívoca entre los sistemas de creencias religiosas de romanos y el "paisaje ideológico" de la religión romana, que es la narrativa maestra idealizada de los conceptos religiosos. Afirma entonces que no entenderíamos dicho paisaje si tratáramos de deducir un sistema normativo en el que las deidades "romanas", "griegas", "orientales" o "extranjeras" pudieran identificarse fácilmente ${ }^{8}$ debido a que "the evolving Roman sacred landscape is the result of constant development, with each generation renegotiating previous traditions, rules and boundaries and rewriting the sacred landscape's spatial matrix"9. Por su parte, G. De Sanctis ${ }^{10}$ retoma la idea de Augé (1992) y afirma que ciertos espacios antropológicos, como el que nos ocupa, resultan 
simbólicos desde tres aspectos: a partir de la relación de cada uno consigo mismo, de la relación de cada uno con los demás, de la relación de cada uno con un pasado común; y se pregunta si son los lugares, en virtud de su fuerza particular, los que despiertan la creencia religiosa, o más bien son éstas las que producen aquellos, llegando a la conclusión de que existe una correspondencia esencial (corrispondenza biunivoca) entre los espacios y la historia de Roma. Si los lugares encuentran confirmación en el relato, por fabuloso que sea, de los textos más antiguos de la ciudad, esos mismos textos pueden ser creíbles, al menos a nivel de "significación" (Bedeutsamkeit), porque se verifican en el presente gracias a la existencia de aquellos espacios que componen la escenografía.

6 Siguiendo estas líneas de investigación nuestro interés radica en interpretar la función de un anticuario como Varrón en la construcción discursiva de un espacio de interés radical para Roma como es el templo Capitolino. ¿Qué elementos destaca el autor al contar las imágenes que lo componen?, ¿qué función cumple la versión contada en Antiquitates Rerum Divinarum en la construcción de la identidad ${ }^{11} \mathrm{y}$ de la memoria ${ }^{12}$ romanas para sus contemporáneos y para los lectores actuales? Si el conocimiento anticuario colaboró en hacer de Roma lugar cercano para sus contemporáneos y los ayudó a formar un sentido firme de su propia identidad ${ }^{13}$, ¿qué sucede cuando esa construcción sobrepasa la dimensión del aspecto material y se conecta directamente con el nivel simbólico que adquieren ciertos monumentos y estatuas compuesta por los mitos y sobre todo por las reflexiones que ciertos agentes culturales, como Varrón, hacen sobre ellos?

7 Nuestro trabajo entonces tendrá en cuenta estos tres niveles de análisis:

8 1. El texto de Moralee, en el que observamos la descripción material, es decir, la presencia de las estatuas de los dioses en cuestión.

9 2. Antiquitates rerum divinarum, en el que leemos el relato mítico etiológico que explica la presencia de esas estatuas en ese espacio descripto por Moralee.

10 3. El análisis de la simbología de ese relato mítico, junto a los comentarios del mismo autor, en el que cada dios representa una cualidad que se extiende en espacio y tiempo: por un lado, no sólo serán rasgos identitarios de un lugar particular de Roma, sino de un espacio que representa el poder de la ciudad entera; por otro, no explicará sólo el presente del autor sino que atravesará los tiempos antiguos para incluso proyectarse a las cualidades alcanzadas por Roma después de la crisis de la República.

\section{Varrón, el anticuario}

11 Momigliano $^{14}$ ha definido el concepto de anticuario comparándolo con el de historiador: (1) los historiadores escriben en orden cronológico; los anticuarios escriben en un orden sistemático; (2) los historiadores producen aquellos hechos que sirven para ilustrar o explicar una situación determinada; los anticuarios recopilan todos los elementos que están relacionados con un tema determinado, ya sea que ayuden a resolver un problema o no. Asimismo, afirma que con Varrón Roma estableció un nuevo estándar, y quizás también le dio un nuevo nombre a la ciencia: antiquitates, y fue con él que el carácter sistemático de este tipo de erudición alcanzó la perfección. Por antiquitates se entiende, entonces, un estudio sistemático de la vida romana de acuerdo con la evidencia proporcionada por el lenguaje, la literatura y las costumbres. 
Kaster ${ }^{15}$, por su parte, define a la investigación anticuaria como una indagación sobre el origen o la naturaleza de prácticas, creencias o instituciones pasadas que no coloquen el resultado de la investigación en una narrativa u otro contexto explicativo más amplio: la respuesta de la investigación a la pregunta “¿Qué hicieron los antiguos con respecto a X?" o “¿Cómo surgió la práctica de $Y$ acerca de X?" se considera satisfactoria en sí misma. Según este autor, la información proporcionada por el este tipo de textos no es utilizada más que para indagar o sistematizar ciertos aspectos de la vida antigua. Si bien en el presente estudio coincidimos en la búsqueda de la sistematización por parte de Varrón, dicha definición no abarca todas las proyecciones que el discurso anticuario emite en tanto constructo discursivo que sin medirse por parámetros de verdad/ mentira permite desentrañar la imagen formada de los antiguos tanto sobre sí mismos para sus contemporáneos como para el futuro. Es importante destacar la función de la creatividad propia del anticuario, siguiendo a Ampolo ${ }^{16}$ y su concepto de "reconstrucción", ésta se define no como sinónimo de falsificación, sino como un proceso que comprende hechos y fábulas reales, falsificaciones y errores, investigación y literatura sin dejar de formar parte de la "memoria colectiva" ${ }^{17}$.

$12 \mathrm{Rüpke}^{18}$, por su parte, afirma que dentro del período de racionalización producido en la República tardía ya explicado y estudiado en trabajos anteriores ${ }^{19}$, la percepción de un cambio acelerado conduce a intentos de documentar y sistematizar (y por lo tanto con frecuencia modificar o inventar) la tradición. Para Rüpke, Varrón fue aún más radical en su propósito - recordemos que la religio no se define como una tradición solamente, sino como una institución, algo "creado" por los humanos. Probablemente, los romanos conocían antes de él las antiguas tradiciones religiosas, tenían recuerdos de templos, de juegos, etc., pero el anticuario va un paso más allá y utiliza el término antiquitates como el instrumento conceptual que le permite viajar atrás en el tiempo a un proceso que lo ayuda a recuperar en el presente, a través de la derivación y de las genealogías, la continuidad con lo que eran antes y así fortalecer su presente con su pasado, y sus orígenes, ¿y por qué no? - agregaríamos nosotros - establecer que esas ideas reconstruidas en el presente con los elementos del pasado establezcan y proyecten simbologías en el futuro del autor. Por esta causa, acordamos con Romano 2003 en relación a lo expuesto inicialmente, pero no así en su definición de "memoria varroniana" como una memoria pasiva, una memoria que se limita a registrar y a archivar todo indiscriminadamente. Si esto hubiese sido así, no existiría una construcción de parte del propio autor que relacione o que explique lo narrado y sólo sería un coleccionista de nombres y ritos. Cuestionamos en qué lugar quedarían sus reflexiones sobre la función de las deidades y sus indicaciones sobre las causas de lo narrado.

13 A continuación analizamos los fragmentos que nos ocupan para ejemplificar las recientes afirmaciones.

\section{Antiquitates Rerum Divinarum}

14 Si seguimos la organización propuesta por Cardauns ${ }^{20}$, la estructura de Antiquitates Rerum Divinarum sería: un capítulo introductorio, tres capítulos que se refieren a los hombres (pontífices, augures, quindecemviri), tres a los lugares (sacella, sacrae aedes, loca religiosa), tres a los tiempos (feriae, ludi circenses, scaenici) y tres a los sacra (consecrationes, sacra privata, sacra publica). Es decir, hombres, lugares, tiempos y cosas. Pero la 
especialización del tópico del texto a analizar necesitó de una adición al trabajo usual del autor y, es por eso que finaliza con tres capítulos sobre los dioses (di certi, incerti, praecipui atque selecti). ${ }^{21}$

Uno de los aspectos más estudiados ${ }^{22}$ de la obra será la definición que hace el autor de lo que llama teología tripartita:

tria genera theologiae...esse, id est rationis, quae de diis explicatur, eorumque unum mythicon appellari, alterum physicon, tertium civile.... Mythicon appellant, quo maxime utuntur poetae; physicon, quo philosophi; civile, quo populi. (RD Frag. 7 = Aug. Civ. Dei 6. 5) Existen tres tipos de teologías, esto es, de la descripción que se despliega acerca de los dioses, y una de ésta es llamada mítica; la segunda, física; la tercera, cívica. Llaman mítica a aquella de la que hacen uso especialmente los poetas; física, a aquella de la que hacen uso los filósofos; cívica, a aquella de la que hace uso el pueblo.

Por lo tanto, plantea un sistema en el que el mito funciona como un aspecto biográfico, siguiendo Assmann ${ }^{23}$, de las divinidades y sus relaciones. La dimensión civil estaría representada por el culto y su importancia política, y la esfera cósmico-filosófica proporciona evidencia de los dioses a través del mundo natural y sus fenómenos ${ }^{24}$. Asimismo, como vimos anteriormente, organiza a las divinidades romanas en tres partes: 1) di certi (libro XIV): designa a todos los dioses de los que Varrón puede determinar con precisión sus atributos y son repartidos según sus competencias propias en dos grupos de importancia equivalente ${ }^{25}$. En el interior de cada grupo, los dioses se unen según el orden cronológico de las diferentes actividades que rigen; 2) Di incerti (XV): según el mismo autor, son los inciertos, de los que tiene dominio vago y 3 ) di praecipui atque selecti (XVI): propone una elección de veinte divinidades (doce masculinas y ocho femeninas) cuya materia, según Lehmann (1997), no es más que la recuperación de elementos anteriores con la aclaración filosófica correspondiente sumada a la lista de dioses elegidos; sin embargo, creemos que dichas reflexiones, pertenecientes a la tercera teología, son centrales ya que invitan a sus contemporáneos a relacionar a sus deidades con fenómenos que están presentes en su vida diaria. Por su parte, Perfigli ${ }^{26}$ al estudiar las divinidades descriptas por Varrón afirma:

I molti dei che abbiamo visto assistere i Romani in ogni singolo momento non sono necessariamente tutti prodotto dello stesso periodo storico o dello stesso contesto culturale.

Por otra parte, en un capítulo posterior Perfigli ${ }^{27}$ señala los comentarios, sobre todo irónicos, de San Agustín a esta división varroniana. Si relacionamos lo postulado con la introducción podemos reafirmar la importancia del contexto cultural del propio anticuario para su selección divina como su posible reconstrucción que incluirá cierta creatividad a la hora de su enumeración así como la inclusión fundamental y trabajada por la crítica sobre las conexiones y reflexiones filosóficas propias del helenismo tratando de unir, según North ${ }^{28}$, el aspecto ritual-cívico, el aspecto reflexivo-filosófico y el aspecto mítico-artístico de las actividades religiosas de los romanos contemporáneos. Se puede detectar entonces, según el historiador ingles, el primer intento identificable en la tradición romana de hacer tal asociación y, por tanto, de crear la posibilidad de englobar todas estas áreas de la vida romana como una especie de unidad. Volveremos a este punto. 
En el marco del primer libro, en el fragmento 34 (Tert. Nat. 2. 9. 6), Varrón afirma que hay dos tipos de dioses, communes et proprii, y comienza a enumerar a los dioses haciendo una genealogía de los reyes que los incorporaron (cf. RD $35=$ Aug. Civ. Dei 4.23).

Luego de la reflexión sobre Hostilio, Varrón relata la elección del Capitolio por parte de Tarquino para el templo de Júpiter:

tres dii, Mars, Terminus et Iuventas, qui maiori et regi suo nullo modo cedere loco voluerunt. Nam ... cum rex Tarquinius Capitolium fabricari vellet eumque locum, qui ei dignior aptiorque videbatur, ab diis aliis cerneret praeoccupatum, non audens aliquid contra eorum facere arbitrium et credens eos tanto numini suoque principi voluntate cessuros, quia multi erant illic, ubi Capitolium constitutum est, per augurium quaesivit, utrum concedere locum vellent Iovi; atque ipsi inde cedere omnes voluerunt praeter illos quos commemoravi, Martem, Terminum, Iuventatem; atque ideo Capitolium ita constructum est, ut etiam isti tres intus essent tam obscuris signis, ut hoc vix homines doctissimi scirent. $(R D 40=$ Aug. Civ. Dei 4.23)

Los tres dioses Marte, Término y Juventas, quienes no quisieron de modo alguno cederle su lugar al mayor y rey; pues, como el rey Tarquino quiso fabricar el Capitolio en ese lugar y que le parecía más digno y acomodado, observó que estaba ocupado por otros dioses, no atreviéndose a deliberar cosa alguna contra (la voluntad) de éstos, y creyendo que voluntariamente éstos cederían ante un dios tan grande y su príncipe, porque allí, donde fue construido el Capitolio, había muchos. A través del augurio preguntó si querían concederle el lugar a Júpiter, y todos ellos quisieron ceder a excepción de aquellos a los que referí: Marte, Término y Juventas; por esta causa el Capitolio fue construido de tal modo, que quedaron igualmente dentro de él estos tres con señales tan desconocidas, que apenas los reconocían los hombres doctísimos.

En este primer fragmento sobre el tópico, Varrón describe el hecho mítico que encontramos en diversas fuentes con elementos comunes: Catón Orig. 1.25; Liv. 1. 55; Liv. 5.54; Dionys. 3. 69; Ov. Fast. 2.658-670; Ov. Fast. 2.683-68429. Varrón, por su parte, representa a un rey Tarquino con un objetivo: construir el Capitolio y consagrárselo a Júpiter, acción que demuestra no sólo por este hecho la pietas del rey, rey cuyo epíteto superbus no resalta justamente dicha cualidad, sino también por respetar la decisión de las numerosas divinidades que allí estaban (quia multi erant illic), razón por la cual necesitaría el permiso de éstas a través de la exauguratio ${ }^{30}$ : el rey, dice Varrón, per augurium quaesivit. Allí nos encontramos con la respuesta negativa de Marte, Término y Juventas a quienes el autor caracteriza, inicialmente, de manera negativa: ut etiam isti tres intus essent tam obscuris signis, ut hoc vix homines doctissimi scirent. Es decir, retoma el hecho mítico, pero "reflexiona" sobre él. En este caso, tam obscuris signis, ut hoc vix homines doctissimi scirent denota que no sólo los dioses tienen signos "confusos, ininteligibles, oscuros, desconocidos ${ }^{31}$ " sino que sólo los hombres doctísimos los reconocerían, relacionando el ámbito de la religio con el ámbito del conocimiento y del estudio, y fundamentando su papel como portador de ese conocimiento para los que les sea complejo interpretar la función de esos tres dioses. Función que explicará en el siguiente fragmento:

pulcherrimum auspicium fuisse dixerunt, ... Martem et Terminum et Iuventatem nec Iovi regi deorum loco cedere voluisse. sic enim ... significatum est, Martiam gentem, id est Romanam, nemini locum quem teneret daturam, Romanos quoque terminos propter deum Terminum, neminem commoturum, iuventutem etiam Romanam propter deam Iuventatem nemini esse cessuram. (RD $41=$ Aug. Civ. Dei 4.29) 
dijeron que había ocurrido el más bello auspicio, que Marte, Término y Juventas no quisieron ceder su lugar al rey Júpiter. Porque, de este modo, fue indicado que el pueblo Marcial, esto es, el romano, a nadie habían de ceder el lugar que ocupasen; que ninguno había de mudar los límites romanos por respeto al dios Término, y que la juventud romana, también por la diosa Juventas, a nadie había de ceder.

El fragmento no sólo explica la causa de la inmovilización de las imágenes divinas sino también transforma los obscura signa desde dos esferas: en primer lugar, la más evidente, en la misma adjetivación: los obscura signa de los dioses se convirtieron en un pulcherrimum auspicium, transmutando los valores negativos del rechazo a ceder su espacio. En segundo lugar, él es el que explicará lo que los augures dijeron (dixerunt) a través del superlativo pulcherrimum por lo que las respuestas de los dioses serán iluminadas a través de la divinatio pero serán narradas y de esta forma racionalizadas, siguiendo el concepto weberiano tomado por $\mathrm{Rüpke}^{32}$, por la explicación sobre el augurio recibido. Nuevamente la esfera religiosa será conectada con el conocimiento que nace de la explicación del superlativo por parte de los augures pero plasmada por parte del autor. A continuación, Varrón enumerará tres características del pueblo romano que definirán su identidad: 1) la elección de Marte de quedarse se debe que a su pueblo, el Marcial, nunca cederá su lugar ante nadie; 2) el dios Término representaría los límites que no serán desplazados y 3) Juventas a la juventud romana que será quien protegerá los límites del posible ataque.

Analicemos con más profundidad la simbología de los protagonistas de este pasaje para destacar el valor de la relación topográfica y teológica para Varrón, teniendo en cuenta que, según Bettini ${ }^{33}$, la identidad divina está determinada por varias características superpuestas pero no coincidentes, incluidos epítetos, imágenes, fábulas, manifestaciones oraculares que incluso pueden contradecirse.

\section{Marte}

Si bien conocemos a Marte como el dios guerrero por excelencia y posee una violencia que sólo le pertenece al mundo divino ${ }^{34}$, Rosivach ${ }^{35}$ se cuestiona qué se suponía que debía hacer Marte si se consideraba dios de la guerra. Para ello estudia las diversas festividades patrocinadas por éste, llegando a la conclusión de que más allá de la identificación con el Ares griego, el Marte romano más que con la guerra en sí misma se relacionaba con la ceremonia de lustratio que cada enfrentamiento requería. Por tanto, afirma que "As a war god, Mars' primary function was purificatory/ protective" ${ }^{36}$.

En los fragmentos que se conservan del texto trabajado tiene ocho menciones ${ }^{37}$, ninguna de las cuales posee una connotación violenta aunque sí guerrera. La primera corresponde al libro I en el que Varrón indica la relación de los reyes con las divinidades. Según éste, entonces, sería Rómulo quien dio por dios a Marte, relación mítica evidente tanto para los contemporáneos como para los lectores actuales, pero junto a Jano, Júpiter, Marte, Pico, Fauno, Tiberino y Hércules. Luego vuelve a nombrarlo en los pasajes analizados, y en el libro XIV lo coloca dentro de los di certi $(R D 185=$ Aug. Civ. Dei 4.21): Marti et Bellonae, ut bene belligerarent, deae Victoriae, ut vincerent. Destacamos entonces que el anticuario caracteriza a Marte como uno de los responsables de que se vaya a la guerra "bene", es decir, la cualidad negativa que puede tener este concepto es apaciguado, incluso transformado, por el adverbio. Por otro lado, más adelante lo enumera en el marco del libro XVI, dentro de los dioses selectos 
$\left(R D 229^{38}=\right.$ Aug. Civ. Dei 7.2) y en su descripción dice deum belli esse (RD $253=$ Aug. Civ. Dei 7.14) descripción que no agrega mayor información. Asimismo, en el apéndice del libro que refiere a Ling. Lat. 5.57, se refiere a él como ab eo quod maribus in bello praeest relacionando etimológicamente el nombre del dios con el sustantivo mas, maris (m.) que no sólo incluye el género masculino sino también tiene una connotación relacionada con el esfuerzo y la valentía ${ }^{39}$.

Si relacionamos dichas cualidades con el pasaje antes analizado, inicialmente, la elección de Marte de quedarse se debe que a su pueblo, el Marcial, nunca cederá su lugar ante nadie. Si profundizamos en el análisis, se interpreta también de esta afirmación que incluso ante pueblos poderosos representados metafóricamente por el intento de desplazo ante Júpiter. Por otro lado, el dios, según lo expuesto por el autor en su obra, traído por Rómulo junto a Júpiter y otras divinidades, sería parte de los dioses ciertos y elegidos cuyo espacio en el Capitolio representa también la cualidad del pueblo romano de conducir de buen grado (bene) la guerra y está ligado a los varones valientes y esforzados. De esta forma, las posibles cualidades negativas atribuidas a la divinidad son trasformadas por la utilización del adverbio por parte de Varrón y por la etimología de la cual deriva su nombre.

\section{Juventas}

El $O C D^{40}$ describe a la deidad no como la diosa de la juventud en general sino la de los Iuvenes, los novi togati, o los jóvenes en edad militar; su función es la de admitir a los hombres en la comunidad y protegerlos como Iuvenes. Asimismo, Daremberg y Saglio ${ }^{41}$ le suman a la caracterización de los jóvenes protegidos por esta deidad la de vigor y coraje: "fournissaient aux armées de la République l'élément par excellence de vigueur et de courage". Al igual que sucederá con el dios Término se le adjudica dicha cualidad inicialmente concebida en Júpiter pero convirtiéndola en una divinidad especial derivada de éste. Sin embargo también se señala el relato mítico retomado por Varrón y por varios autores, como mencionamos, caracterizando el rechazo de la movilidad de la divinidad como "solidité immuable et la jeunesse éternelle de l'empire romain". Clark ${ }^{42}$ en su texto nos invita a dejar de ver a estas divinidades sólo como deidades abstractas y considerarlas como cualidades divinas que tuvieron cultos específicos y un gran interés dentro de la actividad religiosa romana siendo muestras de su pluralismo. Según $A$ Topographical Dictionary of Ancient Rome $e^{43}$ :

\footnotetext{
a temple of Iuventas (Hebe) vowed by M. Livius Salinator on the day of the battle of the Metaurus in 207 B.C., begun by him when censor in 204, and dedicated by C. Licinius Lucullus in 193 (Liv. XXXVI. 36. 5-6). It was burned in 16 B.C. (Cass. Dio liv.

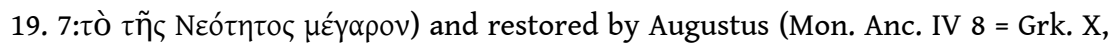

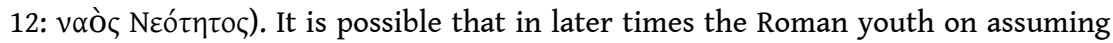
the toga virilis made their offerings in this temple, although this custom was assigned by Lucius Piso to Servius Tullius (Dionys. IV. 15. 5), and the early offerings were made at the shrine of Iuventas on the Capitol.
}

Si bien se destaca la existencia de otro templo de Juventas, es muy probable que las ofrendas de los jóvenes que iban a recibir la toga viril hayan sido directamente en el espacio que nos ocupa, conformando la importancia que esta "cualidad divina" tenía para el proceso de formación de los jóvenes. Por su parte, Bevilacqua ${ }^{44}$ plantea que divinità ideali, como la autora las llama, poseen un significado cultural correspondiente 
a una función social específica, es decir a su utilitas, constituyen, entonces para ella, la representación divina de ciertos comportamientos colectivos considerados correctos $\mathrm{y}$, como tales, útiles para la vida civil. En otras palabras, adorar las virtudes de la deidad, es decir, practicarlas, hace de los romanos buenos ciudadanos.

En los fragmentos varroneanos aparece tres veces, dos pertenecen a los episodios analizados y la tercera, en el marco del libro XVI sobre los dioses ciertos $(R D 142=$ Aug. Civ. Dei 4.11), se la caracteriza como dea Iuventas, quae post praetextam excipiat iuvenalis aetatis exordia. Por lo tanto, Varrón identifica a la divinidad con la del inicio de la juventud, etapa caracterizada por el vigor y el coraje, como vimos anteriormente, pero también al referirse a una edad floreciente puede determinar, como lo hará en los fragmentos analizados, la permanencia en este estado a través del tiempo. Si bien, Daremberg y Saglio señalan esta cualidad como solidez inmutable y la juventud eterna del Imperio romano, como nombramos al inicio de su descripción, el concepto de urbs aeterna, como apunta Edwards ${ }^{45}$ para referirse a otro hecho, comienza a aparecer en el periodo augusteo y su primera mención está en Tibulo, aunque la idea ya es nombrada en el discurso de Cicerón Pro C. Rabirio perduellionis reo en el 63 a. C.

Según Varrón entonces, la continuidad en el espacio del Capitolio por parte de Juventas representa, por un lado, a la juventud romana que será quien protegerá los límites del posible ataque y, por otro, podría estar indicando la juventud eterna de la misma ciudad, idea que luego, en época augustea, se plasmará en uno de los aspectos identitarios más conocidos de Roma como urbs aeterna.

\section{Término}

Según Daremberg y Saglio ${ }^{46}$, esta divinidad nos remonta a los primeros días de Roma y a la organización de la propiedad individual bajo el cuidado y sanción de este dios. La tradición religiosa atribuye a los reyes sabinos, T. Tacio y Numa, la práctica que regula esta división y que la garantiza contra cualquier intromisión, es decir, fueron ellos quienes inventaron los termini, los límites de piedra que sustituyeron, sin hacerlos desaparecer, a los montones de piedras y las simples estacas o troncos de árboles de tiempos primitivos. Según éstos, una consagración piadosa los colocó bajo la protección de Júpiter. El dios Término como divinidad especial separada de aquel no aparecería en ningún lugar antes del Imperio. Asimismo, en el $O C D^{47}$ también lo definen como una característica inicialmente de Júpiter que luego tomó su culto particular. Por su parte, Adkins y Adkins ${ }^{48}$ en su artículo sobre el Capitolio señalan que "[t]he temple of Terminus was not roofed above the site of Terminus Shrine because he had to be under open sky", recordando lo dicho por Servio ${ }^{49}$ y estableciendo que los límites para la conquista romana siempre estarían abiertos.

De Sanctis ${ }^{50}$ ha hecho un trabajo riguroso sobre el simbolismo de esta divinidad. Al referirse al culto del dios, afirma ${ }^{51}$ :

Il culto di Terminus sarebbe stato, dunque, importato, insieme ad altri, dalla Sabina al tempo della guerra con i Romani, nell'ambito di un evento mitico che, come è stato più volte sottolineato, riveste un'importanza fondamentale nella costruzione dell'identità romana (...). All'arrivo di Giove, Saturno e Terminus si separano: mentre il primo scende ai piedi del Campidoglio, ad occupare una posizione che esprime anche topograficamente l'avvenuta sottomissione a Giove, l'altro resta invece al suo posto, sulla cima del colle, finendo addirittura per essere inglobato nel 
nuovo tempio. Esso appartiene al regno di Giove, all'aetas dell'ordine, della divisione, delle disuguaglianze, e in quanto tale non può che essere assunto a simbolo di progresso o di civilizzazione. con Júpiter como un símbolo de progreso o civilización. Por otro lado, como ya hemos analizado en nuestro pasaje, también señala que como Término, o más bien su estatua, había permanecido inmóvil y, por lo tanto, impasible ante el advenimiento de Júpiter, incluso las condiciones tendrían que velar por el respeto a los límites asignados a ellas $^{52}$ : los romanos no solo creían que la inmobilitas de Término se transmitía automáticamente a sus límites, sino que también era un signo de firmeza moral, imparcialidad y un sentido de justicia. Asimismo, el dios representaría el orden que garantizan los límites de la propiedad privada. Luego el autor ${ }^{53}$ relaciona a Término con Marte llegando a la conclusión de que si el dios Término delimita los espacios, Marte los protege. Por otro lado, el hecho de no irse del Capitolio representa una resistencia que perdura en el tiempo ${ }^{54}$ y no sólo, como ya se dijo, se refiere a una característica física (dureza y resistencia) sino que se transforma en una virtud moral.

Júpiter con Término como así de la posición que afirma que Término fue progresivamente transformándose en epíclesis de Júpiter. Para él si el dios Término no se mueve del lugar es porque justamente se impone ante una de las funciones de Júpiter, como destacamos anteriormente, por lo tanto considera que:

Sul confine vi erano insomma impresse non una, ma ben due tutele divine, non sempre perfettamente distinguibili. Lo spazio viene così incardinato secondo un ordine che si crede trascenda il piano meramente umano, che vorrebbe, almeno idealmente, sottrarsi alle recriminazioni e ai tentativi di manipolazione e restare immutato $^{55}$.

En consecuencia, el mito de la inmovilidad se transforma una vez más ya que no sólo el dios Término no quiere dejar su lugar, sino que unirá su espacio al orden (Júpiter).

En relación a su aparición en el texto estudiado, lo encontramos tres veces ${ }^{56}$ : una es la estudiada, la segunda es dentro del libro XVI dedicado a los dioses principales y selectos a quienes les adjudicaría una simbología filosófica. De la mano de Jano, divinidad de los comienzos, se lo nombra Término como divinidad de los "fines": fines vero ad alternum, quem Terminum vocant $(R D 231$ = Aug. Civ. Dei 7.7), es decir que el anticuario lo postula como el fin de las cosas naturales y lo ejemplifica con los meses del año (Iuanuarium Iano - Februarium Termino). Por último se lo nombra de procedencia Sabina, como habíamos visto en Daremberg y Saglio. En consecuencia, creemos que la afirmación De Sanctis coincide con el texto varroneano en cuanto a que es nombrado como un dios principal y como divinidad independiente de Júpiter antes del Imperio. El hecho de que luego se lo asocie a Júpiter como Júpiter Término puede derivar de su ubicación en el templo capitolino como indica el crítico.

Por lo tanto, en el relato contado por Varrón, el dios Término representaría los límites que no serán desplazados: es de destacar que el autor utiliza el verbo commovere que puede aludir a un movimiento de forma violenta ${ }^{57}$ y que responde a la protección de ser conquistados. Asimismo estos límites representan el orden no sólo porque el espacio será compartido por Júpiter sino porque la misma idea de delimitación implica la de 
orden y civilización. Por otro lado, este límite no será sólo material sino también cósmico trazando un final, y con el una forma, al principio creador regido por Júpiter.

\section{Júpiter}

Daremberg y Saglio ${ }^{58}$ destacan las características principales del dios afirmando que el nominativo Júpiter tenía varios equivalentes: Diespiter, Diovis, Jovis. Júpiter fue originalmente, en toda Italia, lo que Zeus fue originalmente en Grecia, un dios físico, dador de luz, maestro del cielo y de los fenómenos celestes: lluvia, relámpago, trueno, el viento y, en general, todo lo que ocurría en la atmósfera y en el cielo dependía de él; maestro de la lluvia, del buen y del mal tiempo, protegía la prosperidad de la naturaleza; para las poblaciones eminentemente agrícolas era un dios cuya importancia sólo podía crecer. Además, las primeras ideas morales llegaron a enriquecer y modificar esta concepción puramente física del dios. Por su parte, el estudio de Cook $^{59}$ sobre la imagen de Zeus lo relaciona con todo lo mencionado anteriormente y estudia sus cultos, y Dumézil ${ }^{60}$ se enfoca en su evolución al estudiar la conformación de la tríada capitolina. Como vimos en el apartado anterior, en relación al episodio estudiado, según De Sanctis ${ }^{61}$ pertenecen al reino de Júpiter el orden, la división, la desigualdad, y como tal sólo puede tomarse como símbolo de progreso o civilización.

Nos interesa ahora la reflexión de la crítica sobre el valor del dios en la obra a estudiar para dilucidar su funcionamiento en el mito mencionado por Varrón pero teniendo en cuenta todas sus apariciones. Lehmann ${ }^{62}$ estudia la relación entre Varrón y Antíoco de Ascalón para destacar su influencia filosófica. Así afirma que la extrema diversidad de fenómenos, las constantes metamorfosis de la materia y los múltiples cambios de los cuerpos que la componen son enigmas que no pueden ser resueltos, según la óptica de Varrón, mas que por una interpretación espiritual del universo y de sus partes. Sin embargo, lo más destacable es que la deificación de esta energía misteriosa, sutil, que penetra y gobierna los elementos del mundo es relacionada por el anticuario con ciertas divinidades y, en esta división, el universo como totalidad orgánica es asimilado a Júpiter en la medida en que este último está identificado como el soberano del ordo mundi, como veremos a continuación. Según Lehmann entonces, la divinidad principal de los romanos poseía una universalidad acorde con su Capitolio y más allá de las contradicciones que se encuentran entre lo planteado por Ascalón y por Varrón, lo que en última instancia le importaba a éste último era el llamado a una adoración ferviente y serena del creador de todas las cosas. Ahí reside, para él, quizás la esencia de una enseñanza filosófica y religiosa que buscaba renovar las formas tradicionales de pensamiento y piedad ${ }^{63}$.

En los fragmentos del texto que nos ocupa, encontramos veintiuna apariciones. En el libro I tiene ocho apariciones, allí se lo caracteriza como hijo de Saturno y Ops $^{64}$; como simbología del anima mundi debido a que "omnes dii deaeque sit unus Iupiter6"; (Iovem in aethere accipimus ${ }^{66}$ ); traído por Rómulo ${ }^{67}$; como portador del rayo ${ }^{68}$; como progenitor de las cosas naturales y de todos los dioses: unus et omnes ${ }^{69}$. En el marco del libro IV al hablar de los libros sibilinos, se nombra su templo en el Capitolio ${ }^{70}$ al igual que en el libro concerniente a los lugares sagrados ${ }^{71}$. En el marco del libro XV sobre los dioses inciertos, vuelve a nombrar a Júpiter como el mismo éter ${ }^{72}$, como el cielo (significare caelum Iove ${ }^{73}$ ) y como el dios más antiguo junto a Juno y Minerva, tríada que representaría el cielo, la tierra y las ideas (como las llamaría Platón ${ }^{74}$ ). Luego lo pone, 
naturalmente, dentro de la lista de los dioses principales y selectos ${ }^{75} \mathrm{y}$ en este marco le da ciertas características: deus est habent potestatem causarum, quibus aliquid fit in mundo ${ }^{76}$, es decir, tiene dominio y potestad absoluta sobre las causas que obran en el mundo. Asimismo, lo compara con Jano diciendo que éste tiene dominio sobre las cosas primeras pero Júpiter sobre las principales y es por eso considerado rex omnium ${ }^{77}$. Luego lo comparará con su padre superándolo por ser simbolizado como la causa de todas las cosas: ideo Saturnum patre a Iove filio superatum, quod ante est causa quae pertinet ad Iovem, quam semen quod pertinet ad Saturnum ${ }^{78}$. Por último será nombrado el mito de su nacimiento ${ }^{79}$ y dentro del apéndice del libro XVI (Ling. Lat. 5.57) se relacionará su etimología con la del verbo iuvare (ayudar).

Es destacable reflexionar sobre la importancia que le da el anticuario a la imagen del dios que desde el comienzo es nombrado gobernando esta dimensión cósmica. Desde su primera aparición Júpiter será relacionado no sólo con la máxima autoridad del panteón sino con el principio creador. Recordemos que la primera dimensión de la presencia o manifestación divina es el cosmos o naturaleza y la cosmología politeísta lo ve como un proceso cooperativo: las deidades cooperan para crear y mantener el mundo ${ }^{80}$ pero, según la mirada del anticuario, tendrá un principio rector que será el mismo Júpiter. En consecuencia, el hecho de que muchas características de las divinidades pasen luego a forman del mismo Júpiter, Varrón lo podría sugerir desde la teología natural en un proceso en el que los principios filosóficos y las deidades de la religio tradicional se unen y retroalimentan. Para él, el dios es parte de todos los dioses y todos los dioses están en él. Asimismo, es la causa que reemplazará al inicio (Saturno) y tendrá la potestad sobre todos los dioses y todas las cosas.

Lo antes enunciado no significa que tanto Marte, como Juventas, como Término no sean considerados por el autor como divinidades individuales, todo lo contrario, creemos que les da a cada uno una simbología especial y una funcionalidad en el entramado religioso; lo que sí postulamos es que en el mismo discurso anticuario que, como nombramos anteriormente, prima la creación, la invención y la superposición de conceptos; la importancia dada al dios principal y su relación con las doctrinas filosóficas frutos del helenismo invita a la teología mítica, plasmada en el discurso sobre el espacio sagrado estudiado, a un diálogo con la teología filosófica: si el poder de Júpiter, con todo lo que ello significa, cedió ante la presencia de las simbologías divinas antes nombradas, de la misma manera el proceso de formación de la religión romana será capaz de dialogar no sólo con otras etnias sino también con otras esferas en un desarrollo constante. Asimismo, dichas deidades, incluido Jupiter, establecen, como dijimos, las cualidades principales de Roma desde ese pasado mítico hasta la posteridad, incluso hasta un futuro que sobrepasa al propio Varrón. Por lo que la definición de las características que la inmovilidad de los tres dioses, Marte, Término y Juventas le otorgan a Roma implican una toma de posición frente a los otros, a lo nuevo, incluso a lo poderosamente nuevo (Júpiter), y frente a lo nuevo o uniéndose a esto, los romanos conservaran sus virtudes basadas en la guerra y conquista llevadas de buen grado (Marte), la protección de los límites y el comienzo de la civilización definida por el orden (Término) y los iuvenes valientes que serán sus habitantes y protectores, e, incluso, la juventud eterna de la misma ciudad (Juventas). 


\section{Conclusión}

Los tres niveles de análisis a los que nos referimos al inicio tienen en cuenta, en primer lugar, la imagen narrada por Moralee que expone un proceso de formación de un espacio radical en Roma. Dicho espacio está formado por objetos materiales (templos, estatuas, calles, etc.), pero el relato del crítico también hace referencia directa o indirectamente a datos que no estarían allí sin las fuentes mítico-literarias que lo han referido. En el segundo nivel de análisis, encontramos la explicación mítica de Varrón sobre la presencia de los diferentes monumentos (en este caso de la construcción del templo de Júpiter y de la inclusión de las estatuas de Marte, Juventas y Término). Por último, se analizó la interpretación y las simbologías que se crean a partir del relato que cobra un nuevo valor si se tienen en cuenta las características propias de lo que Ampolo llama "reconstrucción" como parte de la creatividad del anticuario. De esta forma, la construcción de estos espacios que forman un sistema de signos, según Cancik, integrados no sólo por la materialidad sino también por lo discursivo, según Edwards, Fitzgerald y Spentzou; construyen un tipo de lectura que enlaza y crea una imagen de lo que podría haber sido y significado ese espacio en un momento determinado y qué significa ese espacio hoy una vez construida esa memoria cultural romana a través de todos estos aspectos.

Creemos, por un lado, que el trabajo de Varrón como anticuario no se limitó a guardar nombres y ritos, deidades y mitos sino que les dio a esas deidades una función en la constitución de la memoria romana y que estableció las características principales de Roma, incluso del Imperio romano en la República tardía. Marte, Término y Juventas junto al poder de Júpiter, en el ejemplo que analizamos, le permitieron al autor cuestionar y destacar ciertos rasgos del pueblo romano que constituían y constituirían su identidad tanto para sus contemporáneos como para nosotros. Por otro lado, el episodio inserto en esta obra particular da cuenta de que la construcción de la religión romana, propuesta por Varrón, y de los espacios sagrados es un proceso dinámico que conlleva negociaciones, recreaciones e invenciones no sólo desde lo mítico (los relatos sobre lo divino) sino también desde lo civil (los cultos particulares), lo filosófico (los fenómenos que las deidades representan) y, podríamos agregar, lo simbólico (los valores que conllevan).

\section{BIBLIOGRAFÍA}

ADKINS-ADKINS 1996: L. Adkins - R. Adkins, Dictionary of Roman Religion, New York 1996.

AMPOLO 2013: C. Ampolo, "Il problema delle origini di Roma rivisitato: concordismo, ipertradizionalismo acritico, contesti. I", Annali della Scuola Normale Superiore di Pisa, 5, 2013, 217-284.

AsSMANN 1992: J. Assmann, Das kulturelle Gedächtnis. Schrift, Erinnerung und politische Identität in frühen Hochkulturen, München 1992. 
BENDLIN 2013: A. Bendlin, “The Urban Sacred Landscape”, in P. Erdkamp (ed.), The Cambridge Companion to Ancient Rome, Cambridge 2013, 461-477.

BETTINI 2015: M. Bettini, Il dio elegante: Vertumno e la religione romana, Torino 2015.

BEVILACQUA 2016: L. R. Bevilacqua, "Un pantheon per le virtù - antropologia delle divinità ideali a Roma", Quaderni del Ramo d'Oro On-line, 8, 2016, 128-160.

BEVILACQUA 2018: L. R. Bevilacqua, "Un pantheon per le virtù II - l'utilitas come valore civicoreligioso delle divinità ideali", Quaderni del Ramo d'Oro On-line, 10, 2018, 1-26.

BOGDAN 2016: G. Bogdan, "Forjar la identidad romana: algunas observaciones sobre la sistematización religiosa en Antiquitates Rerum Divinarum de M. T. Varrón”, Praesentia 17, 2016, $1-15$.

BoGDAN 2017: G. Bogdan, "Del rito al mito: Historia y poesía en la representación de la Sibila de Cumas (Antiquitates Rerum Divinarum 4.56, de M. T. Varrón y Metamorfosis 14.102-157, de Ovidio)", Stylos 26, 2017, 33-42.

BRUNT 1989: P. A. Brunt, "Philosophy and Religion in the Late Republic", en M. Griffin and J. Barnes, J. (eds.), Philosophia Togata: Essays on Philosophy and Roman Society, Oxford 1989, 174-198.

CAIRo 2016: M. E. Cairo, “Gianluca De Sanctis, La logica del confine. Per un'antropologia dello spazio nel mondo romano, Roma, Carocci Editore, 2015, 211 pp.”, Cuadernos de Filología Clásica. Estudios Latinos, vol. 36, no. 2, 2016, 356 .

CANCIK 1985-1986: H. Cancik, "Rome as a Sacred Landscape. Varro and the End of Republican Religion in Rome", Visible Religion 4/5, 1985-1986, 250-265.

CARDAUNS 1976: B. Cardauns, M. Terentius Varro, Antiquitates Rerum Divinarum I: Die Fragmente; 2 Kommentar, Wiesbaden 1976.

CIFANI 2018: G. Cifani, "Visibility Matters. Notes on Archaic Monuments and Collective Memory in Mid-Republican Rome”, in K. Sandberg, Ch. Smith (ed.), Omnium Annalium Monumenta. Historical Writing and Historical Evidence in Republican Rome, Leiden-Boston 2018, 390-403.

Соок 1940: A. B. Cook, Zeus: A Study in Ancient Religion, Cambridge 1940.

De SANCTIS 2014: G. De Sanctis, “Spazio” en M. Bettini, W. M. Short, Con i Romani. Un'antropologia della cultura antica, Bologna 2014, 143-165.

De SANCTIS 2015: G. De Sanctis, La logica del confine. Per un'antropologia dello spazio nel mondo romano, Roma 2015.

DíAz-ANDREU 2005: M. Díaz-Andreu, “Gender Identity”, in M. Díaz-Andreu, S. Lucy, S. Babic and D. Edwards (eds.), The Archaeology of Identity. Approaches to Gender, Age, Status, Ethnicity and Religion, London 2005, 13-42.

DUMÉZIL 1966: G. Dumézil, La religion romaine archaïque: avec une appendice sur la religion des Étrusques, Paris 1966.

EDWARDS 1996: C. Edwards, Writing Rome: Textual Approaches to The City, Cambridge 1996.

FitZGERALD - SPENTZOU 2018: W. Fitzgerald - E. Spentzou (ed.) The Production of Space in Latin Literature, Oxford 2018.

GALINSKY 2014: K. Galinsky, Memoria Romana: Memory in Rome and Rome in Memory, Ann Arbor 2014.

KASTER 2010: R. Kaster, "Scholarship", en A. Barchiesi and W. Scheidel (eds.), The Oxford Handbook of Roman Studies, Oxford 2010, 492-504. 
LEHMANN 1997: Y. Lehmann, Varron théologien et philosophe romain, Brussels 1997.

LEWIS-SHORT 1879: C. T. Lewis and C. Short, A Latin Dictionary, Oxford 1879.

LIEBERG 1982: G. Lieberg, “Die theologia tripertita als Formprinzip antiken Denkens”, Rheinisches Museum 125, 1982, 25-53.

Momigliano 1950: A. Momigliano, "Ancient History and the Antiquarian", Journal of the Warburg and Courtauld Institutes 13, 1950, 285-315.

Momigliano 1955: A. Momigliano, Contributo alla storia degli studi classici, Rome 1955.

MORALEE 2018: J. Moralee, Rome's Holy Mountain, Oxford 2018.

NORTH 2014: J. A. North, "The Limits of the "Religious" in the Late Roman Republic", History of Religions 53, 2014, 225-245.

OXfoRD Classical Dictionary 2012: S. Hornblower, A. Spawforth and E. Eidinow (eds.), Oxford Classical Dictionary, Oxford $2012^{4}$.

PÉPIN 1956: J. Pépin, “La «théologie tripartite » de Varron. Essai de reconstitution et recherche des sources", Revue des Études Augustiniennes 2, 1956, 265-294.

PERFIGLI 2004: M. Perfigli, Indigitamenta. Divinità funzionali e funzionalità divina nella religione romana, Pisa 2004.

Perfigli 2014: M. Perfigli, “Politeismo”, en M. Bettini, W. M. Short (eds.), Con i Romani. Un'antropologia della cultura antica, Bologna 2014, 45-86.

ROMANO 2003: E. Romano, "Il concetto di antico in Varrone", en M. Citroni (ed.), Memoria e identità. La cultura romana costruisce la sua immagine, Firenze 2003, 99-117.

Rosivach 1983: J. Rosivach, “Mars, the Lustral God”, en Latomus 42, 1983, 509-521.

RÜPKE 2005: J. Rüpke, “Varro's Tria Genera Theologiae: Religious Thinking in the Late Republic”, Ordia Prima 4, 2005, 107-29.

RÜPKE 2012: J. Rüpke, Religion in Republican Rome. Rationalization and Ritual Change, Philadelphia 2012.

RÜPKE 2014: J. Rüpke, “Varro's Antiquitates and History of Religion in the Late Roman Republic", History of Religions 53, 2014, 246-268.

TARVER 1997: T. Tarver, "Varro and the Antiquarianism of Philosophy", en J. Barnes and M. Griffin, Philosophia Togata II: Plato and Aristotle at Rome, Oxford 1997, 130-64.

VAN NUfFElen 2010: P. Van Nuffelen, “Varro's Divine Antiquities: Roman Religion as an Image of Truth", Classical Philology 105, 2010, 162-188.

\section{NOTAS}

1. MoRALEe 2018, XIII- XIII.

2. La negrita es nuestra.

3. CANCIK 1985-1986, 251.

4. EDWARDS 1996, I-IX.

5. EDWARDS 1996, 12.

6. FITZGERALD - SPENTZOU 2018, 6-10. 


\section{BENDLIN 2013, 463 .}

8. BENDLIN 2013, 466

9. BENDLIN 2013, 467

10. De SANCTIS 2014, $147-151$.

11. Assmann 1992, 74 explica que la identidad colectiva es la imagen que un grupo se forma de sí mismo y con la que se identifican sus integrantes. La identidad colectiva es una cuestión de identificación por parte de los individuos afectados. La identidad es, entonces, un plurale tantum y presupone otras identidades. Sin multiplicidad no hay unidad, sin un modo de ser otro no hay modo de ser propio. En consecuencia, encontramos diversas formas de simbolización de la identidad. Uno de estos será no sólo el relato mítico que construirá tanto Varrón como Tito Livio y Dionisio de Halicarnaso, entre otros. DÍAZ ANDREU 2005, 13-42, por su parte, entiende el concepto de identidad como la identificación individual con grupos más amplios sobre la base de diferencias sancionadas por la sociedad como significativas.

12. Según AsSmANN 1992, 18-19 existen dos registros del pasado, dos extremos sin centro, que corresponden a dos marcos de la memoria distintos entre sí en puntos fundamentales: memoria comunicativa y memoria cultural. Se trata de dos modos de recordar, de dos funciones del recuerdo y del pasado - uses of the past - que hay que distinguir rigurosamente desde el principio, aunque penetren de muchas maneras en la realidad de una cultura histórica. La primera abarca recuerdos relacionados con el pasado reciente, son recuerdos que el individuo comparte con sus contemporáneos. A diferencia de la comunicativa, la memoria cultural es cuestión de mnemotecnia institucionalizada. La memoria cultural es particularmente vulnerable ante las formas politizadas del recuerdo. Los típicos medios de esta forma de memoria son los monumentos, los días conmemorativos y sus respectivos festejos y ritos. Es así que podemos considerar a la memoria cultural como un caso especial de memoria comunicativa. En el marco de su estudio sobre Memoria romana, GALINSKY 2014, 11-12 plantea que la transmisión y la evolución de la memoria cultural pueden tomar muchas formas, por ejemplo, la poesía y no sólo en la época romana. En consecuencia, distingue cómo algunos textos dividen las concepciones entre la historia propiamente dicha y sus reflexiones poéticas y, en este punto, se encuentra la distinción muy debatida entre la historia y la memoria: poemas como Eneida, ejemplifica Galinsky, no constituyen la historia, pero son portadores de la memoria cultural. Por su parte, CIFANI 2018, 390-391, retomando a T. P. Wiseman, afirma que no podemos negar que los monumentos urbanos también jugaron un papel fundamental como hitos públicos en la construcción de una memoria colectiva, y entre ellos, los santuarios religiosos, y los textos que los describen, podemos agregar, constituyen un lugar privilegiado en la construcción de la identidad colectiva y política. Más adelante, retomando a K.-J. HöLKESKAMP (2004-2006), destaca que la topografía sagrada de la ciudad fue uno de los elementos principales de la memoria colectiva de Roma, y el ritual y la conmemoración vinculados a los edificios históricos representaron una de las principales fuentes de la historia (o incluso de la supuesta historia). de la comunidad.

13. EDWARDS 1996, 17.

14. MoMigliano 1950 (= 1955, 67-106).

15. KASTER 2010.

16. AMPOLO 2013, 225-226.

17. Para el estudio del término y su relación con la tradición y la memoria cf. AMPOLO 2013.

18. RÜPKE 2014, 246-268.

19. BOGDAN 2016, 2017.

20. El texto seguirá la edición de CARDAUNS 1976. Para citarlo se usará la abreviatura RD con el número de fragmento propuesto por el crítico. Asimismo se pondrá su equivalencia en los textos posteriores. 
21. Según LeHMANN (1997, 11-14) la organización es puramente varroniana porque no está atestiguada por el culto oficial (no corresponde de ninguna manera a una tripartición del mundo divino como un todo). Los últimos tres libros son consagrados al estudio de los dioses: 1) di certi (libro XIV): designa a todos los dioses de los que Varrón puede determinar con precisión sus atributos, los dioses son repartidos según sus competencias propias en dos grupos de importancia equivalente. En el interior de cada grupo, los dioses se unen según el orden cronológico de las diferentes actividades que rigen. 2) di incerti (XV): son los inciertos, de los que tiene dominio vago y 3) di praecipui atque selecti (XVI): propone una elección racional de 20 divinidades (12 masculinas y 8 femeninas).

22. Cf. PÉPIN 1956, 265-294, LIEBERg 1982; LeHMANN 1997, 332-345, RÜPKE 2005, 107-29; VAN NUfFELEN 2010, 175.

23. ASSMANN 2004, 18.

24. ASSMANN 2004, 17-19.

25. LEHMANN 1997, 11-14.

26. PERFIGLI 2004, 179.

27. PeRfigli 2014, 73.

28. NORTH 2014, 244.

29. Las fuentes pertenecen a diferentes años y tuvieron objetivos diversos por lo que el episodio será adaptado por cada autor en particular.

30. L. ADKINS-R. ADKINS 1996: 'Exauguration: Rites conducted by augurs to ensure that a deity, known or unknown, at a particular site would not be offended by the introduction of a new deity. It could involve deconsecration of a shrine by an augur, with the deity of the shrine being promise an equal or better shrine elsewhere.'

31. LEWIS-SHORT 1879, s.v. obscurus.

32. RÜPKE 2012.

33. BETTINI 2015, 20.

34. DAREMBERG-SAGLIO 1877-1919, s.v. Mars.

35. RosIVACH 1983, 509-521.

36. ROSIVACH 1983, 515.

37. RD 35; 40; 41; 185; 229; 253; 254; Appendix XVI.

38. RD 229: "Jano, Júpiter, Saturno, Genio, Mercurio, Apolo, Marte, Vulcano, Neptuno, Sol, Orco, el padre Libero, la Tierra, Ceres; Juno, la Luna, Diana, Minerva, Venus y Vesta”.

39. OXFORD LATIN DictionARY 1968, s.v. Mas.

40. OXFORD ClASSICAL DictionARY 2012, s.v. Iuventas (H. J. Rose - J. Scheid).

41. DAREMBERG - SAGLIO 1877-1919, s.v. Iuventas.

42. Clark 2007, 11.

43. BALl Platner, ASHBy 2015, s.v. Iuventas.

44. BEVILACQUa 2018, 1.

45. EDWARDS 1996, 99.

46. DAREMBERG - SAGLIO 1877 -1919, s.v. Terminus.

47. OXford Classical Dictionary 2012, s.v. Terminus (H. J. Rose - J. Scheid).

48. L. ADKINS - R. ADKINS 1996, s.v. Terminus.

49. Aen. 9.448: in Capitolio prona pars tecti patet quae lapidem ipsum termini spectat, non termino non nisi sub divo sacrificabatur.

50. De SANCTIS 2015. Agradecemos a la Dra. María Emilia Cairo a través de cuya reseña (CAiRo 2016) nos acercamos a la obra y fue la facilitadora de ésta.

51. DE SANCTIS 2015, 31, 35.

52. De SANCTIS 2015, 43. 
53. DE SANCTIS 2015, 56.

54. DE SANCTIS 2015, 62.

55. DE SANCTIS 2015, 75 .

56. $R D$ 41; RD 231 = Aug. Civ. Dei 7.7; RD Appendix Liber XVI: Ling. Lat. 5.57.

57. LEWIS -SHORT 1879, s.v. commovere.

58. DAREMBERG - SAGLIO 1877-1919, s.v. Jupiter.

59. COOK 1940

60. DUMÉZIL 1966, 291-317.

61. Cf. n. 52 .

62. LEHMANN 1997, 149 y ss

63. Para el estudio de la filosofía en la obra cf. BRUNT 1989; LEHMANN 1997; TARVER 1997; VAN NUFFELEN 2010.

64. $R D 23 b=$ Tert. Nat. 2.2 .

65. $R D 27=$ Aug. Civ. Dei 4.11.

66. $R D 28$ = Aug. Civ. Dei 4.10.

67. $R D 35=$ Aug. Civ. Dei 4.23.

68. $R D 42$ = Aug. Civ. Dei 4.23.

69. $R D$ App. Liber I = Aug. Civ. Dei 7.9.

70. $R D 56=$ Lact. Inst. 1.6.

71. $R D 71=$ Aug. Civ. Dei 6.7.

72. $R D 205$ = Serv. Auct. Aen. 2.296.

73. $R D 206=$ Aug. Civ. Dei 7.28.

74. $R D 206$ = Aug. Civ. Dei 7.28.

75. $R D 229$ = Aug. Civ. Dei 7.2.

76. $R D 235$ = Aug. Civ. Dei 7.9.

77. $R D 236$ = Aug. Civ. Dei 7.9 .

78. $R D 241$ = Aug. Civ. Dei 7.18 .

79. $R D 242$ = Aug. Civ. Dei 7.19.

80. ASSMANN 2004, 1.

\section{RESÚMENES}

El estudio parte de la descripción hecha por Moralee (2018) del templo Capitolino como espacio sagrado. Teniendo en cuenta lo expuesto por Cancik (1986), Edwards (1996) y Fitzgerald Spentzou (2018) sobre la importancia de la construcción de estos espacios desde fuentes míticoliterarias, nuestro interés radica en interpretar la función de un anticuario como Varrón como fuente discursiva de este espacio de interés radical para Roma como es el templo Capitolino: ¿Qué elementos destaca el autor al contar las imágenes que lo componen?, ¿qué función cumple la versión contada en Antiquitates Rerum Divinarum en la construcción de la identidad y de la memoria romana para sus contemporáneos y para los lectores actuales? Creemos que el trabajo de Varrón como anticuario no se limitó a guardar nombres y ritos, deidades y mitos sino que le dio a esas deidades una función en la constitución de la memoria romana. Marte, Término y Juventas e incluso el poder de Júpiter le permiten al autor cuestionar y destacar ciertos rasgos del 
pueblo romano que constituían y constituirían su identidad tanto para sus contemporáneos como para nosotros.

This contribution starts with the description put forward in Moralee (2018) of the Capitoline temple as a sacred space. Basing its reading of the space on Cancik (1986), Edwards (1996) and Fitzgerald-Spentzou (2018), and their arguments about the importance of formation of these spaces from mythical and literary sources, it aims to interpret the function of an antiquarian such as Varro as that of a discursive source on a site of radical interest for Rome such as the Capitoline temple. Which elements does the author emphasize in describing the images that compose this temple? Which functions does the version told in Antiquitates rerum divinarum play in the construction of Roman identity and memory for contemporaries and for today's readers alike? Varro's work as an antiquarian is not limited to recording names and rites, deities and myths, but gives those deities a role in the construction of Roman memory. Mars, Terminus and Juventas, and even the power of Jupiter, in the case-study discussed here, allow him to question and highlight specific features of the Roman people, which had shaped and would keep shaping their identity both for their contemporaries and for us.

ÍNDICE

Keywords: Capitol, space, divinities, Varro, identity

Palabras claves: Capitolio, espacio, divinitades, Varrón, identidad

\section{AUTOR}

\section{GUILLERMINA BOGDAN}

Universidad Nacional de La Plata - Universidad Católica

de La Plata (Argentina)

3 núm. 1274, La Plata (CP. 1900), Buenos Aires,

Argentina

gbogdan(at)fahce.unlp.edu.ar 